\title{
Commentary on the Paper by Gagliano et al: Artificial Neural Networks Analysis of Polysomnographic and Clinical Features in Pediatric Acute-Onset Neuropsychiatric Syndrome (PANS): From Sleep Alteration to "Brain Fog" [Letter]
}

\author{
Rajna Knez (D) ${ }^{1,2}$ \\ 'Gillberg Neuropsychiatry Centre, \\ Institute of Neuroscience and Physiology, \\ Sahlgrenska Academy, University of \\ Gothenburg, Gothenburg, Sweden; \\ ${ }^{2}$ Department of Pediatrics, Skaraborgs \\ Hospital, Skövde, Sweden
}

\section{Dear editor}

A recent article by Gagliano et al emphasized the presence of sleep alterations in pediatric acute-onset neuropsychiatric syndrome (PANS), pointing out a symptomatic overlap with other sleep disorders of well-known immune-mediated pathogenesis, such as narcolepsy and Kleine-Levin syndrome. ${ }^{1}$ While reading the article, I considered the potential role of orexin/hypocretin-system dysfunctionality in sleep disturbances for patients with PANS, alongside the development of other symptoms as part of this syndrome. Importantly, narcolepsy with cataplexy is caused by a loss of orexin-producing neurons in the hypothalamus, and orexin dysregulation has also been suggested to play a role in Kleine-Levin syndrome's pathophysiology. ${ }^{2,3}$ Further, narcolepsy and some neuropsychiatric disorders may share common features, and, though exact mechanisms have yet to be identified, orexin deficiency has been proposed as a pathophysiological mechanism underlying these disorders. ${ }^{4}$ Thus, due to the neuropsychiatric symptoms within PANS, orexin-system dysfunctionality might plausibly play a role in this syndrome's development.

The orexin system participates in regulating several physiological processes ${ }^{4}$ that may be important in the context of PANS. These processes include wakefulness, arousal, sleep/wake behavior, central motor control, cognitive processes, anxiety, reward, motivated behaviors, feeding, and involvement in the micturition reflex. ${ }^{4-8}$ In particular, obsessions and compulsive behaviors might be linked to the orexinergic system and its interactions with the dopaminergic system, ${ }^{8}$ while the presence of orexin cells in the lateral hypothalamus, which is a key site of food intake regulation, ${ }^{4}$ may relate to food restriction among patients with PANS. Considering Gagliano et al's presentation of a putative dysfunctional model that explains the co-occurrence of sleep, cognitive, and motor symptoms in patients with PANS, ${ }^{1}$ the orexin system's role could be emphasized within this symptom's framework.

Given that orexin is a key component of the arousal system and considering the sleep-wakefulness arousal spectrum, ${ }^{5}$ its effects on all aspects across the spectrum 
seem plausible. An optimal balance of arousal allows a person to be awake, alert, creative, and capable of solving problems. ${ }^{5}$ By contrast, as arousal diminishes, a person might experience not only inattentiveness and cognitive dysfunction (understimulation) but also excessive daytime sleepiness. Increased arousal, meanwhile, may cause hypervigilance/insomnia, cognitive dysfunction (overstimulation), panic/fear, and hallucinations/ psychosis. $^{5}$ Thus, the "brain fog" that Gagliano et $\mathrm{al}^{1}$ described might indicate a dysfunction of the orexin system that could manifest with symptoms across the arousal spectrum, affecting such domains as cognitive function, attention, alertness, and vigilance.

In the pathophysiology of movement disorders, that are frequently observed at disease onset in childhood narcolepy with cataplexy, rapid loss of orexin neurons may likely be involved, with possible involvement of secondary dopaminergic abnormalities. ${ }^{2}$ Given several motor deficits associated with the loss of orexins and proposing the orexin system's orchestrating central motor control through homeostatic regulation, ${ }^{6}$ motor phenomena may also be conceptualized as a spectrum wherein the orexin system plays an important role. This conceptualization may help explain the "complex array of 'negative' (hypotonia) and 'active' (ranging from perioral movements to dyskinetic-dystonic movements or stereotypies) motor disturbances" that Plazzi et al described among children who have narcolepsy with cataplexy. ${ }^{2}$ At the same time, it might also explain the observation by Gagliano et al regarding the high prevalence of periodic limb movement disorder (a hypo-dopaminergic condition) among patients with PANS who also exhibited motor and vocal tics (a hyper-dopaminergic condition). ${ }^{1}$

Taken together, orexin-system dysfunctionality, though not completely understood, can be suggested as an important factor in the pathophysiological mechanisms underlying PANS. Most, if not all, PANS symptoms could be proposed to stem from orexin-system dysfunctionality, alongside the sleep alterations that Gagliano et al described. Therefore, within the conceptual framework useful for future empirical research, ${ }^{1}$ the orexin system could also be considered.

\section{Disclosure}

The author reports no conflicts of interest in this communication.

\section{References}

1. Gagliano A, Puligheddu M, Ronzano N, et al. Artificial neural networks analysis of polysomnographic and clinical features in Pediatric Acute-Onset Neuropsychiatric Syndrome (PANS): from sleep alteration to "Brain Fog". Nat Sci Sleep. 2021;13:1209-1224. doi:10.2147/ NSS.S300818

2. Plazzi G, Pizza F, Palaia V, et al. Complex movement disorders at disease onset in childhood narcolepsy with cataplexy. Brain. 2011;134 (Pt 12):3477-3489. doi:10.1093/brain/awr244

3. Wang JY, Han F, Dong SX, et al. Cerebrospinal fluid Orexin A levels and autonomic function in Kleine-Levin syndrome. Sleep. 2016;39 (4):855-860. doi:10.5665/sleep.5642

4. BaHammam AS, Alnakshabandi K, Pandi-Perumal SR. Neuropsychiatric correlates of narcolepsy. Curr Psychiatry Rep. 2020;22(8):36. doi:10. 1007/s11920-020-01159-y

5. Stahl SM, Morrissette DA. Stahl's Illustrated Sleep and Wake Disorders. Cambridge: University Press; 2016.

6. Hu B, Yang N, Qiao QC, Hu ZA, Zhang J. Roles of the orexin system in central motor control. Neurosci Biobehav Rev. 2015;49:43-54. doi:10.1016/j.neubiorev.2014.12.005

7. Kobayashi M, Nomura M, Fujihara H, et al. Involvement of orexin-A on micturition reflex in normal and cyclophosphamide-induced cystitis bladder in rat. Peptides. 2009;30(12):2348-2356. doi:10.1016/j.peptides.20 09.07.025

8. Abounoori M, Maddah MM, Akbari E, Houshmand G, Ardeshiri MR. The effect of Orexin receptor antagonism on Quinpirole-induced compulsive-like checking behavior in rats. Neurotox Res. 2020;38 (1):18-26. doi:10.1007/s12640-020-00196-y

\footnotetext{
Dove Medical Press encourages responsible, free and frank academic debate. The content of the Nature and Science of Sleep 'letters to the editor' section does not necessarily represent the views of Dove Medical Press, its officers, agents, employees, related entities or the Nature and Science of Sleep editors. While all reasonable steps have been taken to confirm the content of each letter, Dove Medical Press accepts no liability in respect of the content of any letter, nor is it responsible for the content and accuracy of any letter to the editor.
}

\section{Publish your work in this journal}

Nature and Science of Sleep is an international, peer-reviewed, open access journal covering all aspects of sleep science and sleep medicine, including the neurophysiology and functions of sleep, the genetics of sleep, sleep and society, biological rhythms, dreaming, sleep disorders and therapy, and strategies to optimize healthy sleep.
The manuscript management system is completely online and includes a very quick and fair peer-review system, which is all easy to use. Visit http://www.dovepress.com/testimonials.php to read real quotes from published authors. 